\title{
Access to the Commonwealth electoral roll for medical research
}

\section{Bebe Loff LLB, MA, PhD, Associate Professor and Director, Michael Kirby Centre for Public Health and Human Rights}

Elissa A Campbel BA LLB(Hons), MPH(PP) Researcher, Michael Kirby Centre for Public Health and Human Rights

Deborah C Glass MA, MSc, PhD, Associate Professor (Research), School of Public Health and Preventive Medicine

Helen L Kelsall MB BS, MPH, PhD Senior Research Fellow, Department of Epidemiology and Preventive Medicine

Claudia Slegers BA, GradDip(Soc), PhD Research Fellow, Department of Epidemiology and Preventive Medicine

Deborah R Zion BA(Hons), MA, PhD, Senior Lecturer Senior Lecture Epidemiology and Preventive Medicine

Ngaire J Brown BMed, MPHTM, FRACGP, Professor of Indigenous Health and Education

Lin Fritsch MB BS, PhD Professor

1 Monash University, Melbourne, VIC

2 Graduate School of Medicine and Faculty of Education, University of Wollongong

Wollongong, NSW.

3 Western Australian Institute for Medical Research, University of Western Australia Perth, WA
Pestern Australia,

bebe.loff@monash.edu

doi: 10.5694/mjall.11620

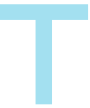
he Commonwealth electoral roll (ER) is the best source of representative samples of Australian adults for public health research purposes. ${ }^{1,2}$ The Commonwealth Electoral Act 1918 provides that ER data may be released for medical research in accordance with national privacy guidelines, ${ }^{3,4}$ on request and payment of a fee. ${ }^{5}$ The Australian Electoral Commission (AEC) relies on the Federal Privacy Commissioner's definition of medical research when making decisions regarding the disclosure of elector information. ${ }^{6}$

In July 2010, we sought a random sample of 9000 electors from the AEC for a study seeking to establish the views of Australians on privacy and participation in epidemiological research. The study was funded by the National Health and Medical Research Council (NHMRC) and approved by Monash University Human Research Ethics Committee (MUHREC). Over the next year, despite our cooperation in responding to numerous requests, the AEC refused to provide the sample. The AEC expressed two major concerns: that MUHREC did not have the expertise to deal with privacy issues and that our study was not medical research.

\section{Expertise of the university ethics committee}

The AEC claimed that MUHREC did not meet the privacy guideline requirements established pursuant to $\mathrm{s} 95$ of the Privacy Act 1988 (Cwlth), as it failed to satisfy the AEC that its members had the qualifications and experience to deal with privacy. The AEC also claimed that MUHREC did not provide evidence that it had weighed the public interest in the study against the public interest in maintaining the privacy of ER data, or explain how and why it reached its conclusions.

Monash University is confident MUHREC functions in accordance with all relevant requirements. ${ }^{7}$ It is far from clear why it should be necessary to provide the AEC with evidence of the qualifications and expertise of MUHREC members, or the content of deliberations and reasons for decisions. It cannot be the AEC's role to second-guess the university's compliance with requirements of a third party. Nonetheless, this evidence was provided to the AEC.

\section{Definition of medical research}

Although our study satisfied the NHMRC and its peer reviewers, the AEC argued that the study did not meet its definition of medical research. The AEC uses the Australian information and privacy handbook definition of medical research, ${ }^{6}$ consistent with s 6 of the Privacy Act, which

\section{Sumnary \\ - In the 2010-11 financial year, there was a dramatic reduction in the approvals granted by the Australian Electoral Commission for access to samples of the adult population derived from the electoral roll for the purposes of public health research. \\ - Much time and effort has been expended in making applications without success. Researchers refused access to electoral roll samples must rely on sampling methods that are not as robust and that may produce less reliable data. \\ - We outline a set of recommendations that, if adopted, will result in a fairer system for obtaining access to the electoral roll for public health research.}

merely states that "medical research includes epidemiological research".

We obtained an informal opinion from the NHMRC, which confirmed that, in its view, the research was medical research.

There is little empirical research about why Australians choose to participate in epidemiological research or how sensitive they are about researchers accessing their health information. Our study aimed to provide reliable evidence on which to base ethical decision making concerning the balance to be struck between protecting privacy and the conduct of epidemiological research. While the research does not investigate illness or treatments, its findings could make a contribution to the conduct of health research and thus to health.

\section{Impact of AEC decisions}

Other researchers have reported similar experiences. The $A E C$ 's interpretation of medical research may have led to decreased numbers of researchers requesting or receiving ER data. In the 2010-11 financial year, the AEC granted nine ER extracts for medical research or health screening purposes. This represents a sharp decline from 45 recipients in 2009-10 and 36 in 2008-09. The Box shows the number of requests granted by the AEC by financial year, derived from the relevant AEC annual reports. The numbers may vary slightly because it is difficult to determine whether multiple requests have been granted for individual studies. The number of requests granted for 2010-11 is out of keeping with the general trend. The number of refusals is not recorded.

The AEC attributes the decline to a decreased number of researchers requesting extracts. ${ }^{2}$ 


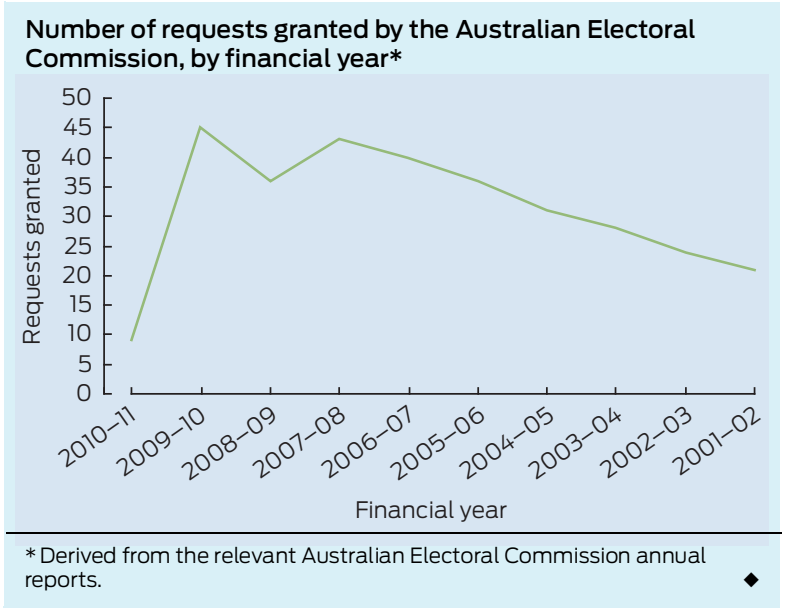

Personal communications suggest that there may have been an increase in the rate of refusals. Monash University researchers have also been refused access to ER data for research into the safety of domestic greywater because (among other things) the AEC claimed that the study went beyond medical research. Access was refused because the AEC considered that the ER data was to be used "to identify persons who reside in premises with access to greywater" and that information derived from the research might benefit water utilities.

Other universities are experiencing similar problems. Researchers at the University of Melbourne have been refused access to ER data for a project that commenced in the 1990s, for which access was previously granted. An Australian National University researcher stated: "My successful application was finalised on 16 November 2010. Because of the size of the project, we have applied for [electoral] roll data in three separate requests. The first two (both in 2010) were successful. The third was submitted on 8 February 2011 (rejected), 28 February 2011 (rejected), 5 June 2011 (rejected) and last week on 12 December 2011." A researcher from the University of Newcastle started a project for which access to AEC data had been approved, but has since been refused access. The Australasian Epidemiological Association and the Australasian Faculty of Public Health Medicine have both expressed their concerns to the government.

The AEC is deciding what constitutes medical research, without providing any right of appeal, and it rejects, without further inquiry, the validity of the membership and processes of human research ethics committees (HRECs) and the decisions that they make. Much effort has been expended by researchers in attempting to comply with AEC processes, with little success. Some researchers now rely on less robust sampling methods, which may produce less accurate results.

\section{Proposed reforms}

The primary purpose of the ER is to register the entitlement to vote. ${ }^{2}$ Under paragraph 1.3 of the NHMRC privacy guidelines, $^{8}$ the AEC has the discretion to decline to disclose personal information for use in medical research, even when that research has HREC approval consistent with privacy guidelines. ${ }^{9}$ Nonetheless, the AEC's interpretation of medical research seems overly restrictive. A more transparent process is desirable.

The release of ER data for medical research should be to applicants whose research is approved by a properly established HREC whose decisions are consistent with the privacy guidelines. ${ }^{8}$ Neither HRECs nor their approvals need be reinvestigated by the AEC. The AEC is no better placed than an HREC to determine whether medical research meets requisite privacy standards. Additional privacy requirements imposed by the $\mathrm{AEC}$, such as requiring third parties to execute deed polls, are acceptable but should be clearly specified and equitably applied. ${ }^{8}$

The AEC uses a purposefully narrow definition of medical research, to capture a limited range of research and subject it to enhanced privacy requirements. Concerns about its narrow scope and the need to clarify what medical research means have been discussed since 2003. ${ }^{10}$ In 2008, the Australian Law Reform Commission recommended that:

- the Privacy Act be amended to provide that "research" include the compilation and analysis of statistics; and

- research rules cover any human research in the public interest, not just health and medical research. ${ }^{11}$

In 2009, the Government indicated its support for the Commission's proposed amendments. ${ }^{12}$

Medical research involves more than clinical research. It includes research that may examine the features of populations for the purpose of protecting or improving health. This category of research is more likely than clinical research to seek ER access. No other database with equivalent inclusiveness is accessible to researchers.

Prima facie, research should be considered to be medical research if it is funded by the NHMRC or equivalent funding bodies drawn from the Australian Competitive Grants Register. If such research is judged by the AEC not to be medical research, then the AEC should provide its reasons. These reasons should be reviewable first internally and, if necessary, by the Administrative Appeals Tribunal. The addition of a review process will maintain public confidence in the ER by ensuring inappropriate disclosure of elector information is prevented, while more properly reflecting current medical research practice.

\section{Conclusion}

It is entirely within the AEC's discretion whether to release ER information. It is concerning that NHMRC-funded projects that are judged to fulfil ethical requirements are unable to access ER data and proceed as intended. The proposed changes take into account the importance of maintaining the integrity of the ER and preserving individual privacy while also promoting medical research that benefits the health of all Australians.

\section{Competing interests: No relevant disclosures.}

\section{Provenance: Not commissioned; externally peer reviewed.}

1 O'Toole J, Rodrigo S, Sinclair M, Leder K. The Australian Electoral Commission Roll has good utility for "niche" household recruitment in population health studies. Aust N Z J Public Health 2009; 33: 137-139. 


\section{Ethics and law}

2 Australian Electoral Commission. Annual report 2010-2011. Canberra: AEC, 2011.http://www.aec.gov.au/About_AEC/Publications/Annual_Reports/2011/ files/aec-annual-report-2010-2011.pdf (accessed Dec 2011).

3 Commonwealth Electoral Act $1918 \mathrm{~s} 91 \mathrm{~A}(2 \mathrm{~A})$ (c).

4 Electoral and Referendum Regulations 1940 (Cwlth) reg 9.

5 Commonwealth Electoral Act 1918 s 90B(4), item 2.

6 Australian information and privacy handbook. Sydney: CCH Australia, 1998, reissued 2011: paragraph 40-040.

7 National Health and Medical Research Council, Australian Research Council, Australian Vice-Chancellors Committee. National statement on ethical conduct in human research. Canberra: Australian Government, 2009.

8 National Health and Medical Research Council. Guidelines under section 95 of the Privacy Act 1988. Canberra: Commonwealth of Australia, 2000. http://www.nhmrc.gov.au/_files_nhmrc/publications/attachments/e26.pdf (accessed Mar 2013).
9 Australian Electoral Commission. Supply of elector information for use in medical research. 2011. http://www.aec.gov.au/Enrolling_to_vote/About_ Electoral_Roll/medical_research.htm (accessed Dec 2011).

10 Privacy Commission. Review of the guidelines under section 95 of the Privacy Act 1988: joint summary. 2003. http://www.privacy.gov.au/materials/types/ reports/view/6621 (accessed Dec 2011).

11 Australian Law Reform Commission. For your information: Australian privacy law and practice. ALRC report 108. Vol. 3. Canberra: Commonwealth of Australia, 2008: recommendations 65-1-65-3. http://www.alrc.gov.au/sites/ default/files/pdfs/publications/108_vol3.pdf (accessed Dec 2011).

12 Ludwig J. Enhancing national privacy protection: Australian Government first stage response to the Australian Law Reform Commission report 108 "For you information: Australian privacy law and practice". 2009. http:// www.dpmc.gov.au/privacy/alrc_docs/stagel_aus_govt_response.pdf (accessed Dec 2011) 